\title{
Integrated treatment with endodermal massage, proprioceptive rehabilitation, viscoelastic, plantar orthosis and myofascial manual therapy on skin graft: case report
}

\author{
Raoul Saggini, ${ }^{1}$ Giovanni Barassi ${ }_{\text {ABCDEF }}$, Piera A. Di Felice ${ }_{\text {ABCDEF }}^{1}$, Roberta Frasci ${ }_{\text {ABCDEFG }}$ Ira Dodaj $^{2}{ }_{\text {ABCDEF }}$, \\ Simona M. Carmignano ${ }_{\text {ABCDEFG }}$, Rosa G. Bellomo ${ }^{2}{ }_{\text {ABCDEFG }}$ \\ ${ }^{1}$ Department of Neuroscience and Imaging, Postgraduate School in Physical and Rehabilitation Me- \\ dicine, G. d' Annunzio University, Chieti, Italy \\ ${ }^{2}$ Faculty of Physiotherapy G. d' Annunzio University, Chieti, Italy
}

Key words: endodermal massage, myofascial, graft, skin, rehabilitation

\section{Introduction}

Skin grafting is a surgical procedure by which skin or skin substitute is placed over a burn or non-healing wound to permanently replace damaged or missing skin or provide a temporary wound covering. A piece of skin is surgically removed from a donor area to replace skin in a defective or denuded area (as one that has been burned). [1]

The term "graft" by itself commonly refers to either an allograft or an autograft.

An autograft is a type of graft that uses skin from another area of the patient's own body if there is enough undamaged skin available, and if the patient is healthy enough to undergo the additional surgery required. An allograft uses skin obtained from another human being. Donor skin from cadavers is frozen, stored, and available for use as allografts. Skin taken from an animal (usually a pig) is called a xenograft because it comes from a nonhuman species. Allografts and xenografts provide only temporary covering because they are rejected by the patient's immune system within seven days. They must then be replaced with an autograft.[2]

Skin grafts can be:

\section{SPLIT-THICKNESS GRAFTS}

A split-thickness skin graft involves the epidermis and a little of the underlying dermis; the donor site usually heals within several days. The surgeon first marks the outline of the wound on the skin of the donor site, enlarging it by $3-5 \%$ to allow for tissue shrinkage. The surgeon uses a dermatome (a special instrument for cutting thin slices of tissue) to remove a split-thickness graft from the donor site. The wound must not be too deep if a split-thickness graft is going to be successful, since the blood vessels that will nourish the grafted tissue must come from the dermis of the wound itself. The graft is usually taken from an area that is ordinarily hidden by clothes, such as the buttock or inner thigh, and spread on the bare area to be covered. Gentle pressure from a well -padded dressing is then applied, or a few small sutures used to hold the graft in place. A sterile non adherent dressing is then applied to the raw donor area for approximately three to five days to protect it from infection.[3]

\section{FULL-THICKNESS GRAFTS}

Full-thickness skin grafts may be necessary for more severe burn injuries. These grafts involve both layers of the skin. Full-thickness autografts are more complicated than partial-thickness grafts, but provide better contour, more natural color, and less contraction at the grafted site. A flap of skin with underlying muscle and blood supply is transplanted to the area to be grafted. The back and the abdomen are common donor sites for full-thickness grafts. The main disadvantage of full-thickness skin grafts is that the wound at the donor site is larger and requires more careful management. Often, a split-thickness graft must be used to cover the donor site.[4]

The essential conditions for a good graft are:

- receiving area has to be well vascularized able to give rise to neoangiogenesis;

- A strong connection between graft and receiving area to avoid the formation of hematoma or seroma between the two surfaces;

- Accurate immobilization of the graft to promote revascularization.

To keep the graft well bonded and fixed to the bottom of the receiver you need to make, after the skin transfer, a compressive medication with bandages or sponges throughout the period necessary to engraftment.[5]

\section{Case presentation}

We report the case of a male patient who underwent a skin graft after excision of a nevus that had since birth located on the right foot.

As time went by, nevus has reached the size of $15 \mathrm{X} 14 \mathrm{~cm}$ by undergoing to chromatic, size and margins changes.

Following a dermatological specialist examination, it was decided to evaluate the histological nature of the nevus. 
The first surgical consultation had suggested the use of the muscles of the shoulder for the reconstruction of all the layers removed of the foot.

However, given the young age of the subject, so debulking surgery would certainly have presented difficulties in the construction of vascular anastomoses. For this reason, it was decided to perform a full-thickness allograft using tissue of the thigh. The tissue of thighs being particularly lapse could allow for better rooting and physiological healing of the tissue.

The skingraft was performed on September 24th 2003 when the patient was twelve years old. The surgical team removed skin tissue up to about $1 \mathrm{~cm}$ deep and it have been used several metal clips and sutures (450) to close the wound .

Medicated bandages (ialuronic acid associated with argentic sulphadiazine) have been used as graft medication to improve healing.

The patient was given antibiotics to prevent the development of infections. It was prescribed the use of a gypsum tutor to prevent from direct load.

Within two months wound dressings were carried out to gradually remove the sutures and prevent from the formation of pathological scars or keloids.

The patient came to our observation in 2012: at observation the skin graft appeared slightly elastic, hyperpigmented and slightly vascularized. The thickening of the tissue suggested the presence of many subcutaneous scar adherences. The portion most affected was scar edge. Patient had mild tenderness, itching and discomfort, especially evident when the skin is stretched during walking and load.

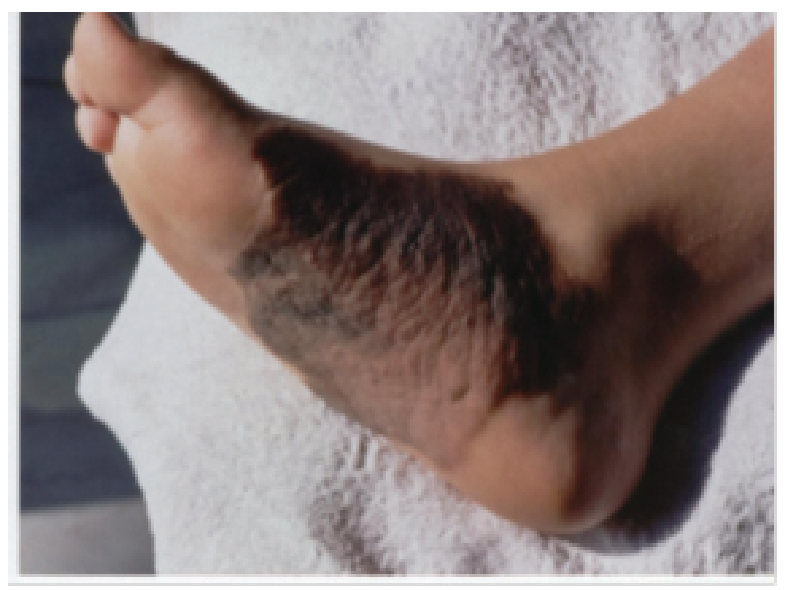

Fig.1 Skin graft area

We proceded to evaluate the patient by physiatric clinical examination, instrumental postural analysis using digitized baropodometric and stabilometric examination, for the overall morphological plantar biomechanics and postural assessment.

The patient showed a clear external rotation of the lower limbs and a attitude in pronation of the foot, especially the right. This attitude was also confirmed by instrumental assessment.
Furthermore, the patient showed a frontal plane asymmetry that is particularly evident on the level of the acromial processes and triangles of the size. Physiological curves of the spine were altered on the sagittal plane with increased dorsal kyphosis and head anteposition.

\section{Rehabilitation treatment}

We planned a local and postural rehabilitation project in order to achieve an improvement in the tissue tropism of the graft tissue and reprogram the global posture.

In the first phase, the patient was treated 3-4 times a week, for 4 weeks.

Each session consisted of a endodermal massage through the use of a technological device to vacuum effect. This technique involves the treatment of the connective tissue under the skin using vacuum aspiration (vacuum).

Suction creates an uplift of the tissue into small plicae allowing a deep massage that improves blood circulation. Rollers on the skin create a specific pressure that determine general tissue relaxation. The pressure and aspiration have a modeling painless and non-invasive effects, which in the meantime is also associated with a good draining.

This mechanical action detach the scar's deep adherences to promote tissue tropism by stimulating fibroblasts. [6][7][8][9]

In the same session the grafted area was treated with manual myofascial therapy, treating carefully the scar edge where the tissue appeared more compromised. [10]

The tissue is initially prepared using touch technique: with hands rapid movements tissue is warmed on surface and so local vasodilation is increased as well as blood affluence.

After touch technique, kneading technique is performed in stitched join areas. Kneading technique is carried through with a skin massage using thumb and forefinger and then trough manipulation as if you were just „knead the dough for the bread."

After that, through specific movements, adhesions can be dissected and fibrous tissue mobilized. In the end of therapeutic session, another stretching exercise is performed.

The scar tissue is always stretched thanks to facilitations, i.e. to the side in which skin movement is eased.[11][12][13]

In this way there is also an indirect action on hypomobile side, working on the adhesions and facilitating the detachment of deep tissues. The position reached in stretching is to be kept for some seconds, in order to obtain a long lasting tissue modification.

It was used manual myofascial therapy for detaching adhesions and reduce soft tissue contractures; restore the correct local blood perfusion of the tissue and reduce pain. [14] 


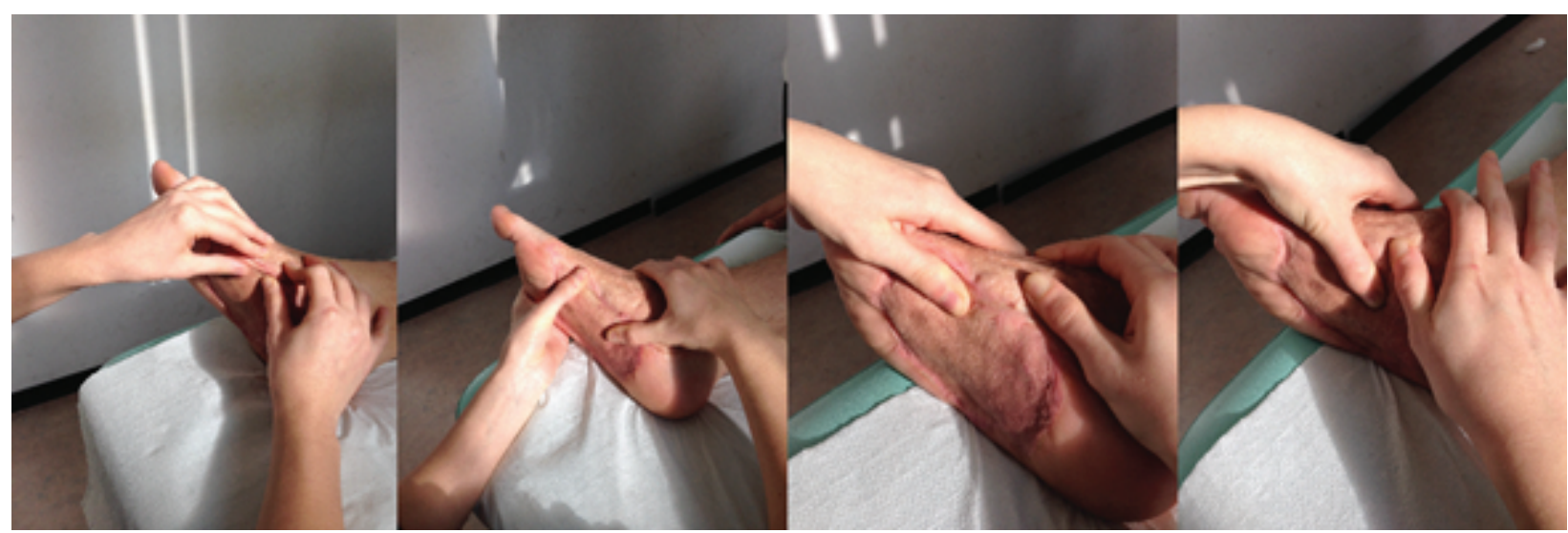

Fig 2. Manual therapy

It was prescribed customized viscoelastic orthotics to restore and enhance the proper proprioceptive stimuli and to increase total contact area on order to redistribute biomechanical forces and load. Usage of foot orthotics lies in their ability to alter foot posture, leading to kinematic postural changes of the lower limb and pelvis. Customized viscoelastic orthotics normalize the foot-ground reaction and control vertical and shear forces on the foot during the stance phase. It had to be worn all day while performing common activities of daily living.[15][16][17][18]
In the end of each session other exercises act to improve sensitivity of particularly damaged skin. To reach the target, the patient was asked to recognize stimuli of various nature, including thermal stimuli.

Patient was assessed at T0, T1 (4 weeks) and T2 at the end of the rehabilitation protocol.

We kept on evaluating the patient by physiatric assesment, instrumental postural analysis using digitized biometric and stabilometric examination, for the overall morphological plantar biomechanics and postural assessment.

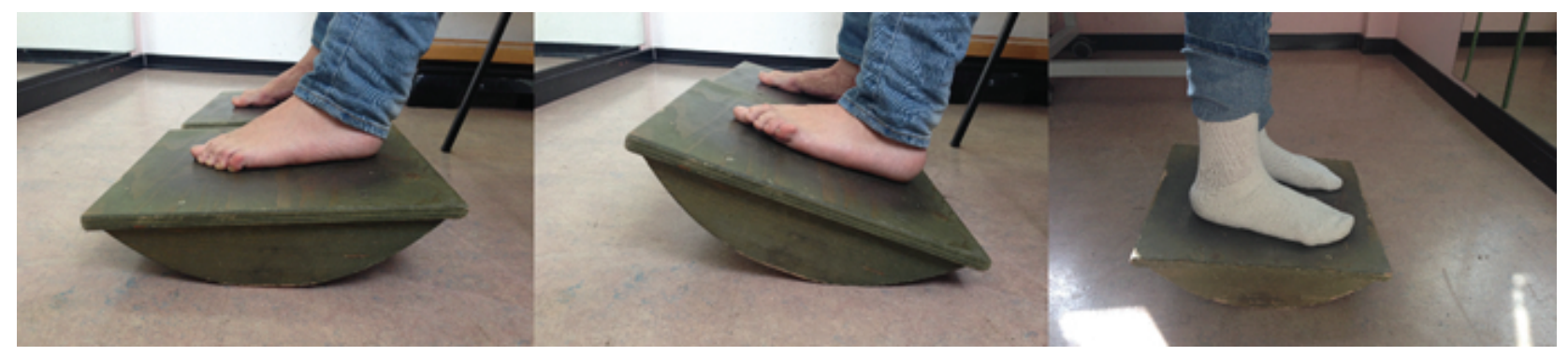

Fig.3 Proprioceptive exercises

The session concluded with the manual treatment of muscles considered most dysfunctional: suboccipital, iliopsoas and piriformis muscles (the latter treated bilaterally).[19][20]

The second phase began about a month later.

The patient was treated 3 times a week for 3 weeks. In this part of treatment the proprioceptive re-education has played a major role.

During early sessions, the seated patient was asked to perform exercises with proprioceptive tablets in order to have stimulation of foot plant receptors and to mobilize actively and successfully lower limb muscles and joints, specially ankle one.

As the patient became able to perform this exercise correctly, he was asked to conduct improving balance training.

The patient had to maintain balance standing on the proprioceptive tablet, at first on both feet then on one only. [21]
For assessing subjective and objective aspect of the skin graft we used POSAS scales (Patient and Observer Scar Assessment Scale): This scale allows to obtain both the subjective evaluation of the patient is the objective of the examiner who administers it.[22][23]

The objective evaluation of the operator is asked to identify, on a numeric scale that ranges from a minimum of 1 to a maximum of 10 , the situation of four parameters which relate to the receiving area graft: vascularization, pigmentation, thickness and elasticity.

The highest score, 40, corresponds to the „worst scar ever".

The subjective component the patient responds to a questionnaire that identifies, using the same numerical scale before, parameters such as the presence of pain, itching, chromatic variations, changes in texture, varying the thickness of the skin and surface irregularities. Also in this case the maximum score obtainable, 60 , corresponds to „worst scar ever.” 
A numerical scales ranging from a minimum of 0 to a maximum of 10 for the sensitivity of the skin:

- The tactile sensitivity was superficial and epicritica Evaluated by the touch of the skin with a cotton swab;

- The tactile sensitivity was superficial and protopatica Evaluated by pricking the skin by means clustering of a needle.

\section{Results:}

In static baropodometry and gait analysis were evaluated in the three times T0, T1 and T2, the total area of the podalic support on the ground, the load applied on each foot and the podalic axis.

On the basis of the values obtained, it is possible to note that although there has been slight worsening between $\mathrm{T} 0$ and $\mathrm{T} 1$, at $\mathrm{T} 2$ the subject shows a more symmetrical a bearing surface on both plantar surfaces (dx: T0 221.5 $\mathrm{cm} 2$, T1 $204 \mathrm{~cm} 2$, T2 $150.75 \mathrm{~cm}^{2}$; sin: T0 $209.5 \mathrm{~cm}^{2}$, T1 $181.75 \mathrm{~cm}^{2}$, T2 $138.75 \mathrm{~cm}^{2}$ ) as reported in graph 1 . The subject also, which initially showed a slight foot flat-footedness, shows a reduction of contact with the ground, with the formation of the podalic isthmus.

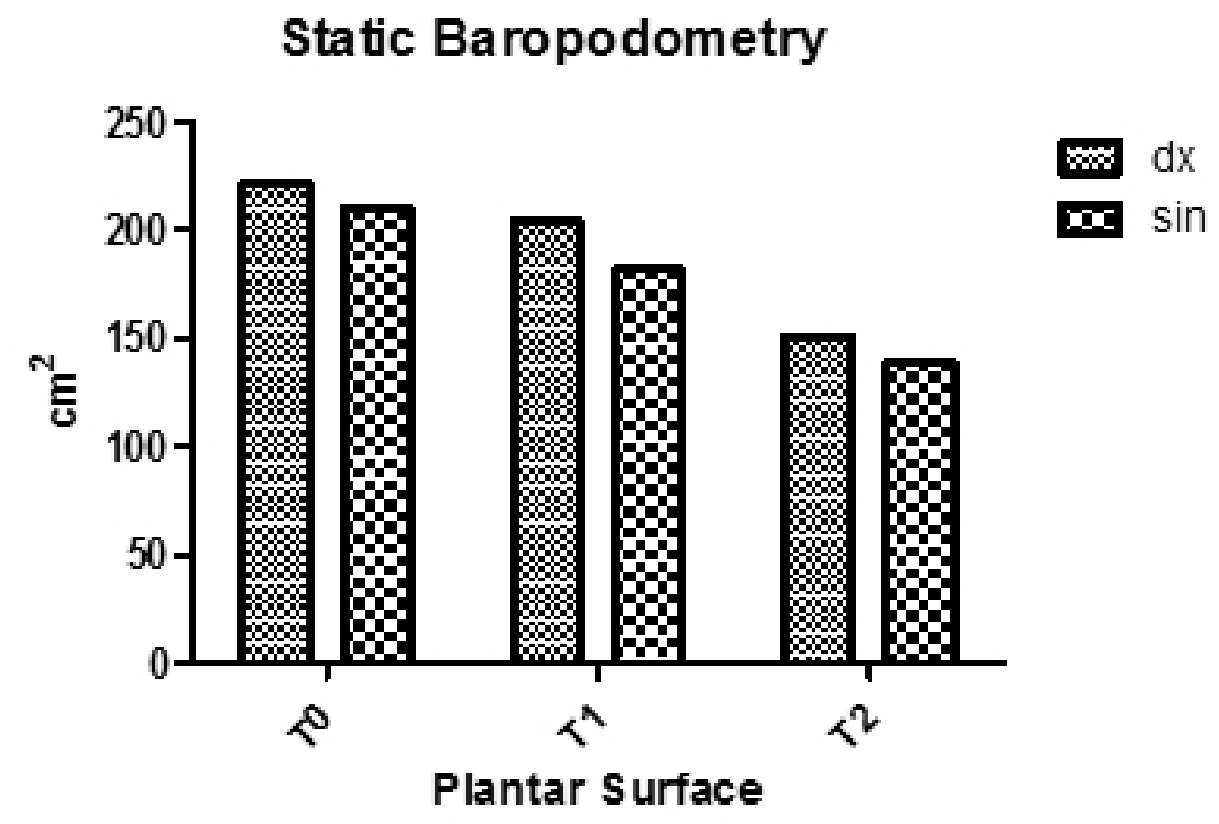

Graph 1 shows the values, expressed in $\mathrm{cm}^{2}$, of the footprint of each foot examination baropodometric static in the three times evaluation.

The assessment of percentage of the load can a progressive load redistribution bringing a situation of improved symmetry (dx: T0 52.48\%, T1 56.91\%, T2 52.07\%; sin: T0 47.52\%, T1 43.09\%, T2 47.93\%) as shown in graph 2. 


\section{Static Baropodometry}

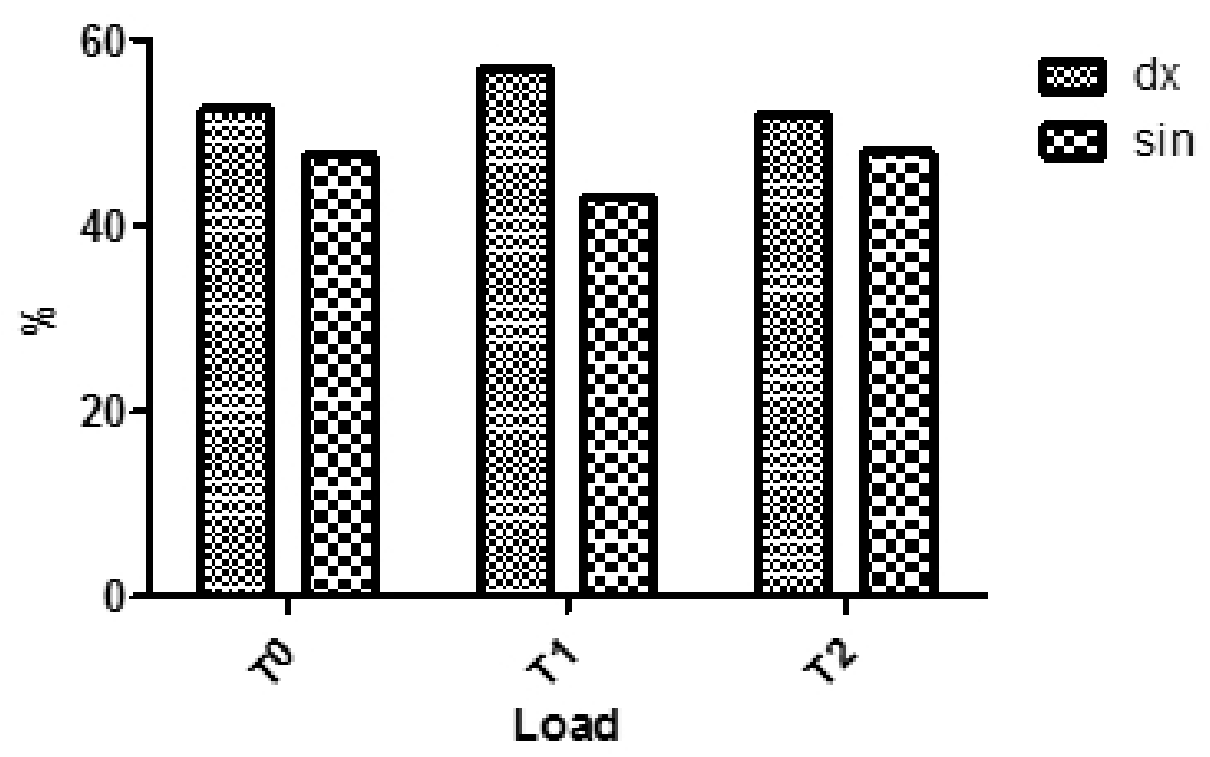

Graph 2 shows the percentage of the load supported by each foot, in statics, assessed at the podobarometrical examination performed in the three times $\mathrm{T} 0, \mathrm{~T} 1$ and $\mathrm{T} 2$.

Foot Axis: the values of the angle formed by each foot compared the horizontal plane, measured during the examination baropodometric dynamic at T0, T1 and T2. This values allows the assessment of attitudes in internal and external feet rotation (dx: T0 $0.1^{\circ}, \mathrm{T} 11.64^{\circ}, \mathrm{T} 27.59^{\circ}$; sin: T0 $4.51^{\circ}, \mathrm{T} 18.31^{\circ}, \mathrm{T} 29.46^{\circ}$ ) as shown in graph 3 .

With regard to this parameter, it is possible to note that, from a $\Delta$ of about $4^{\circ}$, we get, in $\mathrm{t} 2$ to a goniometric difference of about $2^{\circ}$, revealing a global situation more symmetric.

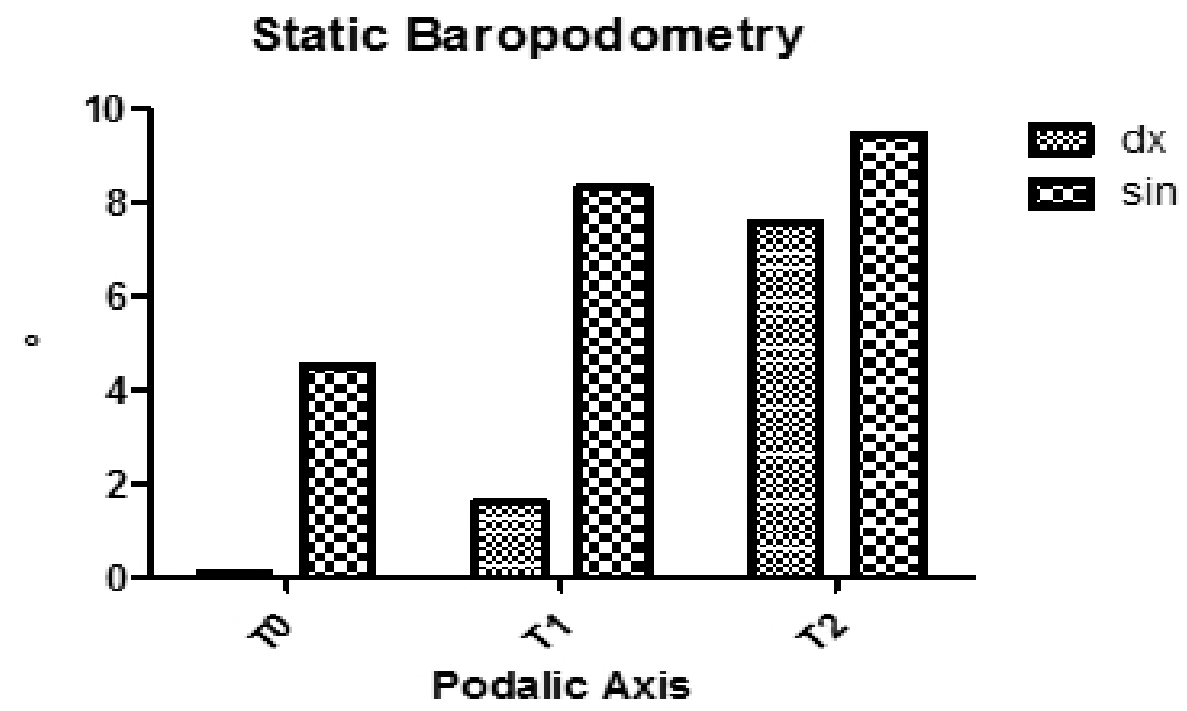

Graph 3 shows the value of the angles formed by the axis of each foot on the horizontal plane. Although the baropodometric examination is carried out in the forced position with parallel feet, this parameter allows us to measure the deviation in podalic internal or external rotation. 
The baropodometric test allowed us to evaluate, in dynamics, the values relative to the average pressure exerted by each foot on ground during gait, the load applied on each foot and the podalic axis.

The average value the pressure applied by each foot has increased significantly (dx: T0 558.03, T1 577.46, T2 876.61; sin: T0 531.61, T1 515.2, T2 814.96). This indicates a an improvement of the kinetics of the step and a better balance during gait (graph 4).

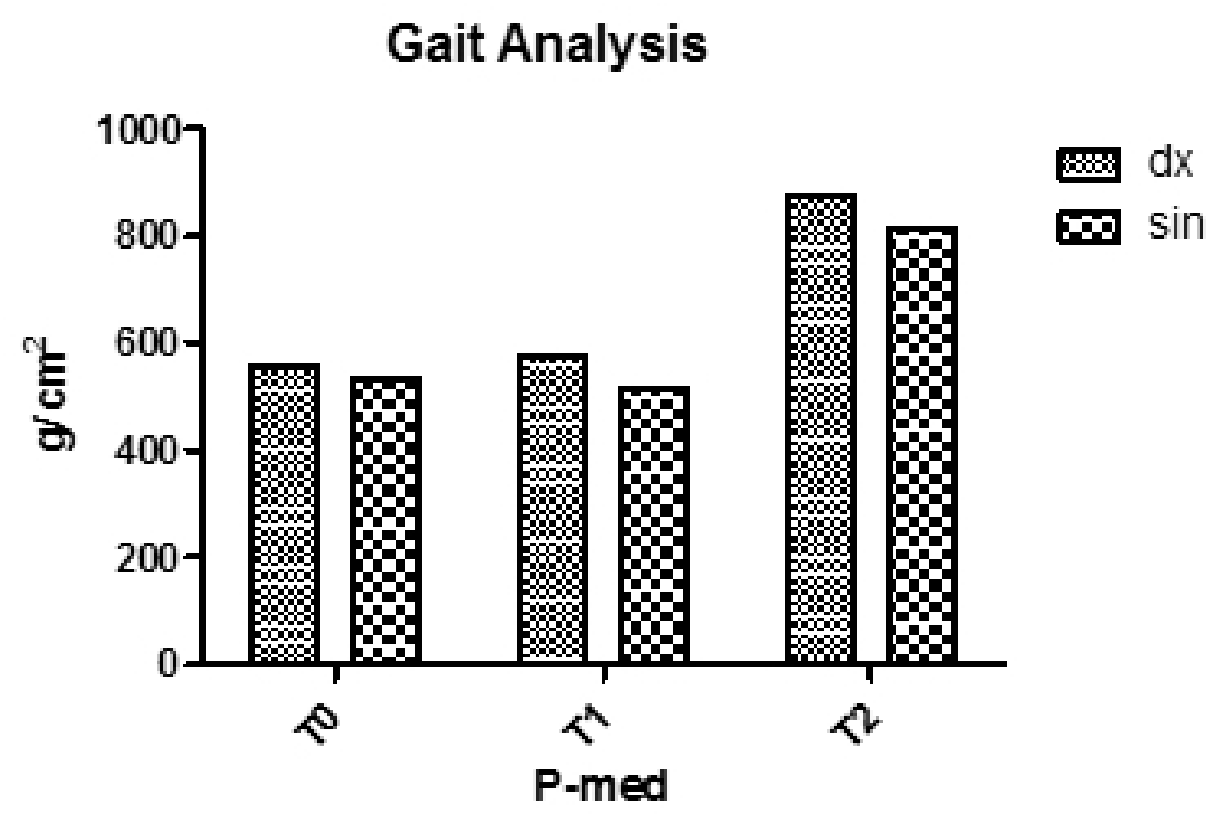

Graph 4 shows the values of the average pressure that each foot exerts on the ground during walking, assessed through gait analysis in times $\mathrm{T} 0, \mathrm{~T} 1$ and $\mathrm{T} 2$.

The difference in the percentage of load between left and right limb shows a significant reduction from the first evaluation $\mathrm{T} 1$. It then remains stable throughout the rest of the treatment, until to T2 (dx: T0 52.86\%, T1 50.48\%, T2 50.92\%; sin: T0 47.14, T1 49.52, T2 49.08). The symmetry is highlighted then also during gait (graph 5). 


\section{Gait Analysis}

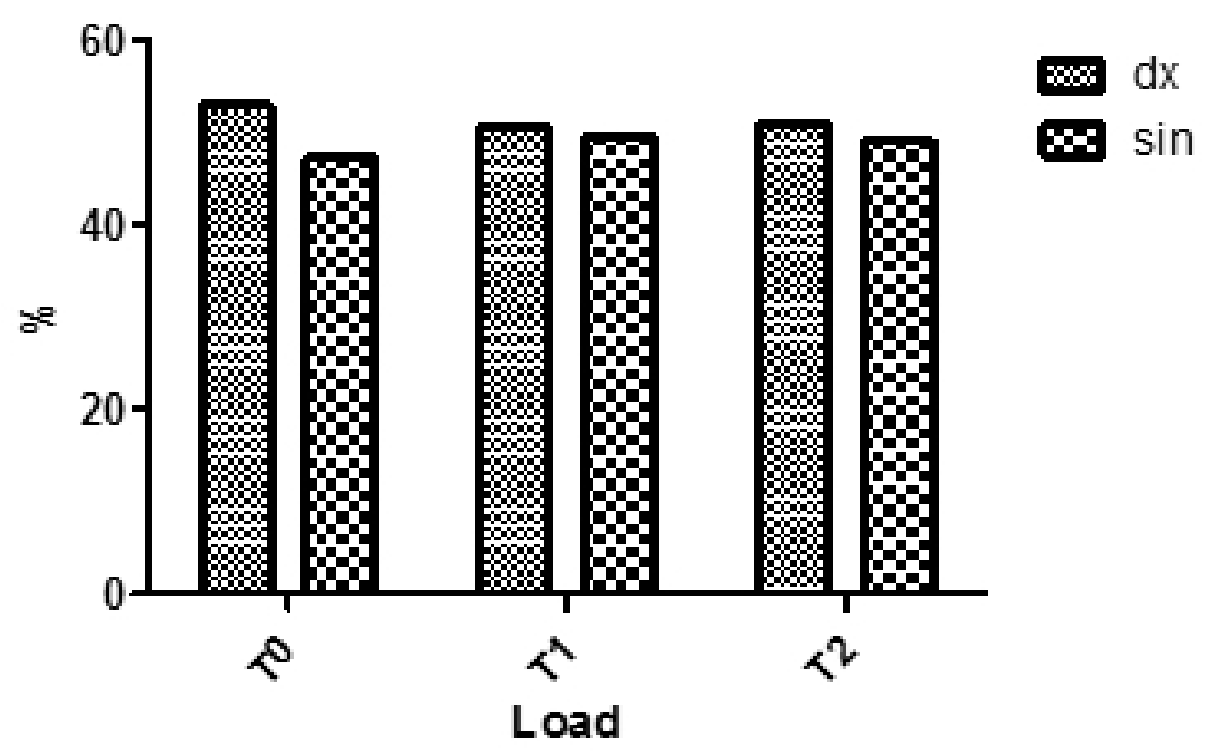

Graph 5 shows the values expressed as a percentage, of the load supported by each foot during gait analysis.

During gait, it showed an increase of podalic lateralization interesting both feet (dx: T0 5.57, T1 5.55, T2 7.43; sin: T0 11.64, T1 14.19, T2 9.78).

Lateralization, however, is symmetric, indicating a homogeneous load distribution and better symmetry propulsive strength (graph 6).

\section{Gait Analysis}

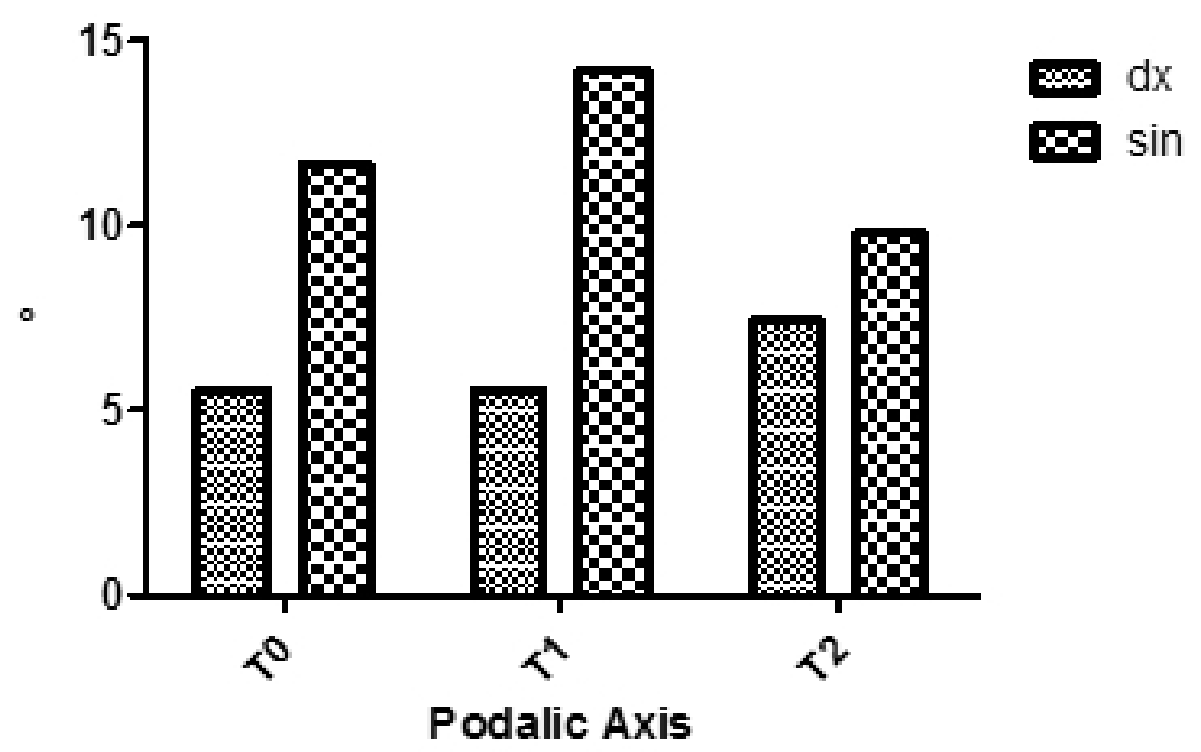

Graph 6 shows the values of the angle formed by each foot compared to the horizontal plane, measured during gait analysis in each evaluation carried out at T0, T1 and T2. 
There was evidence of a significant improvement in sensitivity to evidential numerical evaluation rating scale.

During the first sessions, the subject took about 60 minutes before being able to discriminate sensory stimuli proposed. In the last session, the patient was able to recognize immediately the different nature of the stimuli, showing a greater sensory perception (graph 7).

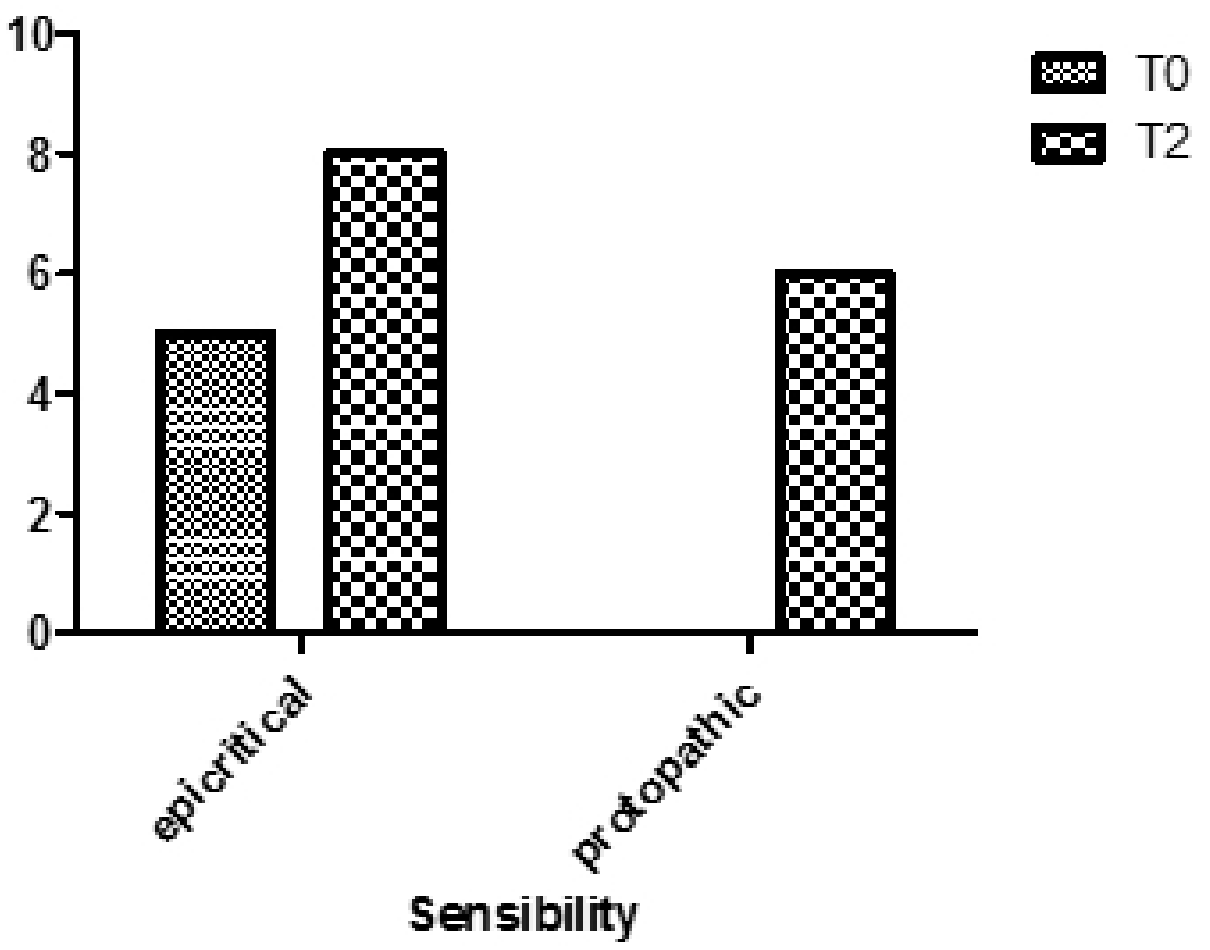

Graph 7 shows the trend of sensitivity in the two assessments carried out in T0, before starting the experimental protocol, and T2, after finishing the treatment proprioceptive aimed to improving the same parameter.

We used the scale POSAS to identify improvements in vascularization and trophism.

The score has gone from 41 to 20 for the POSAS Patient scale and 32 to 15 for the Observer POSAS scale.

The patient reports that he no longer had itching on the site of the graft, as well as that he no longer saw the formation of sores of the same phenomena. Observing the skin, although much more rosea due to the increased vascular supply of obtained, achieved uniform of color. Evaluation tactile skin shows more elastic and, at the same time are almost absent fibrous adhesions found at T0. 


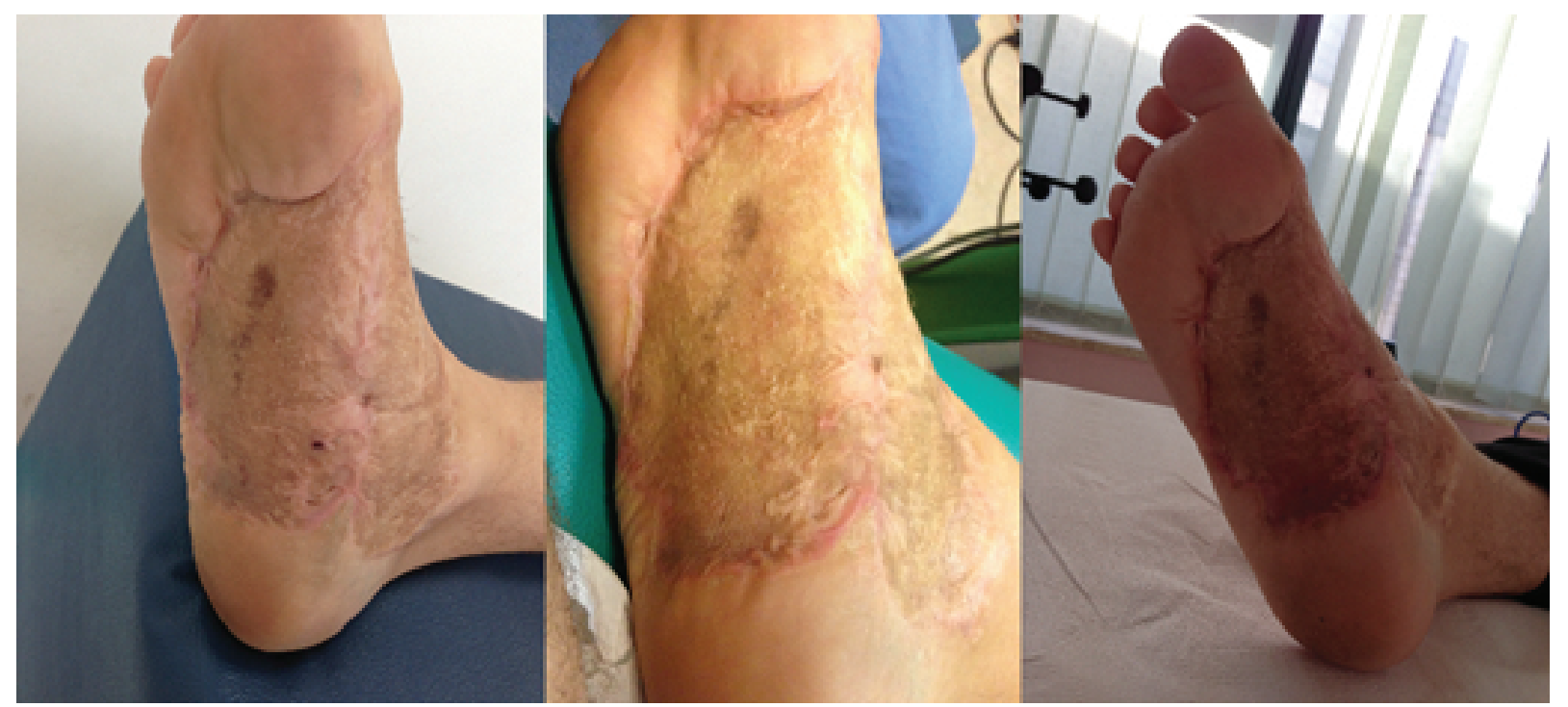

Discussion

It is now generally accepted that human standing posture is maintained through a central postural program assisted by various types of sensory feedback of mainly labyrinthine, visual, muscular and cutaneous origin that together contribute to postural stabilisation as well asbeing the basis of a body posture representation. (Gurfinkel et al. 1988; Horak \& Macpherson, 1996; Mergner \& Rosemeir, 1998).[24][25][26]

Motor reactions are well known to occur in response to experimental manipulation of each of these sensory modalities.

In particular, postural responses are induced by electrical stimulation of the labyrinth (Lund \& Broberg, 1983; Fitzpatrick et al. 1994; Day et al. 1997) [27][28] [29], vibration of ankle muscle groups (Eklund, 1972; Roll \& Roll, 1988; Kavounoudias et al. 1999a),[30][31] [32] vibration of the foot soles (Saggini 2011)[33], or exposure to moving visual scenes (Dichgans et al. 1975; Lestienne et al. 1977; Bronstein \& Buckwell, 1997).[34] [35][36]

There are several lines of evidence in the recent literature that suggest a contributing role of cutaneous receptors from the foot sole in controlling standing balance.

The interactions between two particular modalities that are heavily involved in stance control: muscle proprioception and tactile afferents from the foot soles. Skin receptors in the foot sole are sensitive to contact pressures and may be sensitive to potential changes in the distribution of pressure. [37]

Together, the integration of all these somatosensory inputs appears to provide important information about the body's position with respect to the supporting surface.

For example, mechanical stimulation of the plantar skin during quiet stance has been shown to evoke postural sway that is highly correlated with the cutaneous stimuli (Maurer et al. 2001).[38]
Reduction of this cutaneous information, either by cooling or placing a cuff on the leg, is associated with an increase in postural sway (Orma, 1957; Asai et al.1992).[39][40]

Furthermore, compensatory stepping reactions to sudden postural perturbations are also affected by reduced plantar support information (Perry et al. 2000).[41] Skin receptors may therefore be able to detect not only the movement of the centre of pressure as it moves towards the boundaries of the base of support, but may also be able to initiate postural reflexes that promote a more stable standing position (Do et al. 1990).[42]

Cutaneous afferents were classified as slow adapting when they responded continuously to maintained indentations. If the receptor responded only to the onset and removal of the stimulus, it was classified as fast adapting. Receptors were classified by type based on the following: slow adapting type I receptors had small receptive fields with multiple hotspots; slow adapting type II receptors had a single hotspot with large, obscure receptive fields and a higher skin stretch sensitivity; fast adapting type I receptors had small receptive fields with multiple hotspots; and fast adapting type II receptors had large, obscure receptive fields with a single hotspot and a higher sensitivity to vibration.[43]

The receptive field areas for units in the foot sole were also three times greater than the fields of units found in the hand (Johansson \& Vallbo, 1980).[44] However, unlike the hand, the positions of the receptive fields were randomly distributed throughout the plantar surface of the foot.

There did not appear to be an accumulation of type I receptors in the toes, nor was there any preferred spatial distribution for receptors in the foot. In contrast, there is a proximodistal density gradient for receptors in the hand, including a congregation of type I receptors in the fingers (Johansson \& Vallbo, 1979). [45] The spatial arrangement of receptors in the palmar skin allows the hand to acquire information about skin deformation 
during object manipulation (Johansson \& Vallbo, 1983). [46]

While cutaneous information from the plantar skin is also important, the foot is primarily involved in weight-bearing actions and would not require as high a level of acuity as that found in the hand.

In comparison with the cutaneous receptors in the glabrous skin of the foot sole, the tactile afferents innervating the la the lateral border of the foot and calf had lower force thresholds and smaller receptive fields (Trulsson, 2001).[47] Any activity from skin receptors in the foot sole may be important for signaling that the foot is in contact with the supporting surface (Kavounoudias et al. 1998).[48]

The wide dispersal of receptors throughout the foot sole would ensure that skin receptors would be able to code for contact pressures, and hence the position of the foot with the ground. Interestingly, there were a limited number of units documented in the longitudinal arch. If a preferential distribution exists, the accumulation of receptors in the anterior aspect of the foot, the lateral border and the heel would correspond to the critical regions of the foot that take up the majority of the body's weight in loaded conditions (Perry et al. 2000).[49]

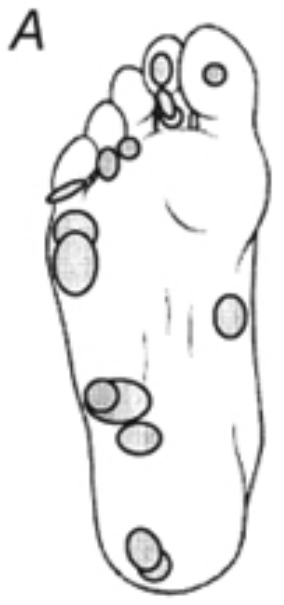

SAI

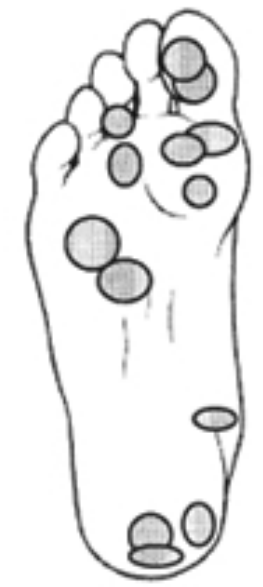

SAll
Altered plantar pressure sensation may contribute to the postural and balance deficits seen.

When compared with younger (50-60 years old) controls, elderly subjects ( $>85$ years) exhibit greater sway velocities that may be related in part to somatosensory deficits in the lower legs and feet (Pyykko et al. 1990). [50]

Astronauts returning from prolonged exposure to microgravity exhibit increases in 'tremor-type' postural sway frequencies (Cherepakhin et al. 1973; Kozlovskaya et al.2001) that might be due in part to hypersensitivity of the cutaneous foot soles . [51][52]

It is therefore clear that the function can affect the podalic ascending pathways influencing responses descendants, especially if it is underlined the that extensors and flexors muscle chains start from the foot coordinating the dynamics of the body.

The patient in the case report showed a skin graft so extensive and fibrotic adhesions that resulted in an alteration of the sensitivity of the sole of the foot, which over the years has generated a change in the global postural control. Considerable theoretical and experimental evidence exists to suggest that feedback from plantar cutaneous afferents may be important for the maintenance of upright stance and posture we propose a rehabilitation protocol with aimed to determine an improvement of local tissue tropism in order to achieve an improvement of sensory stimulation of the foot skin and global posture.

The association with proprioceptive exercises, manual therapy, the use of viscoelastic orthotics aimed to recover the proprioceptive stimulus aimed at improving the postural global view of the significant correlations between the inputs from the foot and posture. Aware of the necessity to support our data with a more scientific level and of the necessity to expand the casuistry, we hope to open a discussion on this topic in the scientific field.

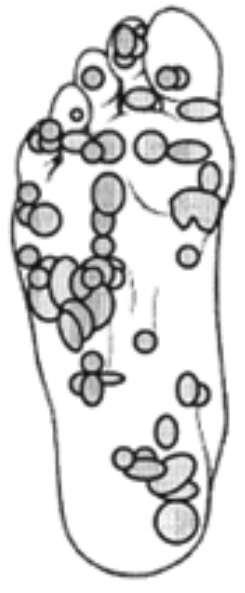

$\mathrm{FAl}$

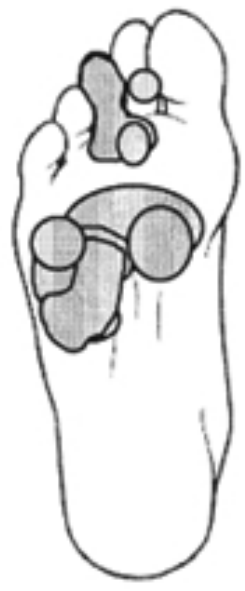

FAll

\section{References:}

1. Jones J.E., Nelson E.A., Al-Hity A. Skin grafting for venous leg ulcers. The Cochrane database of systematic reviews , $2013 ; 1$ :CD001737.

2. Mackay D.R., Miraliakbari R., Skin grafts. Operative Techniques in General Surgery. 2006; 8(4);197-206.

3. Snyder R.J., Doyle H., Delbridge T. Applying Split -Thickness Skin Grafts: A Step-by-Step Clinical Guide and Nursing Implications. Ostomy Wound Management; 2002: 990-996.

4. Revis D.R., Seagal M.B., Skin Grafts, Full-Thickness. eMedicine ; 2002.

5. Darwish A. Indications of Skin Graft, Skin Grafts Indications, Applications and Current Research. Marcia Spear red., 2011; ISBN: 978-953-307-509-9. In Tech, 
Available from: http://www.intechopen.com/books/ skin-grafts-indication.

6. Watson J., Fodor P.B., Cutcliffe B., Sayah D., Shaw W. Physiological effects of endermologie ${ }^{\oplus}$ : A preliminary report . Aesthetic Surgery Journal; 1999; 19 (1) ; 27-33.

7. Leffler M., Horch R.E., Dragu A., Bach A.D. The use of the artificial dermis (Integra) in combination with vacuum assisted closure for reconstruction of an extensive burn scar. A case report. Journal of Plastic, Reconstructive \& Aesthetic Surgery, 2010; 63, 3235.

8. Molnar J.A., DeFranzo A.J., Hadaegh A. Acceleration of Integra incorporation in complex tissue defects with subatmospheric pressure. Plast Reconstr Surg 2004;113:1339:46.

9. Roques C. Technique in burn scars: A 14 years experience $\mathrm{LPG}^{\oplus}$ Technique 1rst Scar Meeting; March 29-April 1, 2006; Montpellier .

10. Lewit K., Olsanska S. Clinical importance of active scars: abnormal scars as a cause of myofascial pain. Journal of Manipulative and Physiological Therapeutics, 2004;27(6).

11. Beard G. Wodd EC: Massage: Principles and Techniques.Philadelphia, 1984.

12. Rodríguez R.M., Galán del Río F. Mechanistic basis of manual therapy in myofascial injuries. Sonoelastographic evolution control. Journal of Bodywork and Movement Therapies,2013;221-234.

13. Hunter G. Specific Soft Tissue Mobilisation in the Treatment of Soft Tissue Lesions. Physiotherapy, 1994; $15-21$.

14. Greenmann Ph E: Principi di terapia manuale. Futura publishing society,2001.

15. Saggini R.,Bellomo R.G., Iodice P., Lessiani G. Venous insufficiency and foot dysmorphism: effectiveness of visco-elastic rehabilitation systems on veno-muscle system of the foot and of the calf. International Journal of Immunopathology and Pharmacology, 2009; 22(33 Suppl):1-8.

16. Nigg B.M., Herzog W., Read L.J. Effect of viscoelastic shoe insoles on vertical impact forces in heel-toe running. Am J Sports Med ,1988;16(1):70-6.

17. Albert S., Rinoie C. Effect of custom orthotics on plantar pressure distribution in the pronated diabetic foot. J Foot Ankle Surg., 1994 ; 33(6):598-604.

18. Kendall J.C., Birdb A.R., Azari M.F. Foot posture, leg length discrepancy and low back pain - Their relationship and clinical management using foot orthoses - An overview. The Foot, $2014 ; 75-80$.

19. de las Peñas C.F., Campo M.S., Carnero JF, Page MJC. Manual therapies in myofascial trigger point treatment: a systematic review. Journal of Bodywork and Movement Therapies; 2005; 27-34.

20. Travell J.G., Simons D.G.: Myofascial Pain and Disfunction: The trigger point manual. The Upper Extremities. Baltimore; Williams \& Wilkins: 1992.

21. Cote K.P., Brunet M.E., Gansneder B.M., Shultz S.J.
Effects of Pronated and Supinated Foot Postures on Static and Dynamic Postural Stability. Journal of Athletic Training, 2005; 40(1):41-46.

22. Martijn B.A., van der Wal Wim E., Tuinebreijer B., Verhaegen P., Middelkoop E., Paul van Zuijlen Rasch. Analysis of the Patient and Observer Scar Assessment Scale (POSAS) in burn scars. Qual Life Res, 2012; 21:13-23.

23. Raklyar E., Zloty D.M. Use of a Patient and Observer Scar Assessment Scale to Evaluate the V-Y Advancement Flap for Reconstruction of Medial Cheek Defects. Dermatologic Surgery, 2012; 1968-1974.

24. Gurfinkel V.S., Levik Y.S., Popov K.E., Smetanin B.N., Shlikov V.Y. Body scheme in the control of postural activity. In Stance and Motion. red. Gurfinkel V.S., Ioffe M.E., Massion J., Roll J. P. New York ; Plenum Press: 1988 s. $185-193$.

25. Gurfinkel V.S., Lipshits M.I., Mori S., Popov K. E. The state of stretch reflex during quiet standing in man. Progress in Brain Research, 1976; 44, 473-486.

26. Kavounoudias A., Roll R., Roll J.P. Foot sole and ankle muscle inputs contribute jointly to human erect posture regulation Journal of Physiology , 2001; 532.3, pp.869-878.

27. Lund S., Broberg C. Acta Effects of different head positions on postural sway in man induced by a reproducible vestibular error signal. Physiol Scand,1983; 117(2):307-9.

28. Fitzpatrick R., Burke D., Gandevia S.C. Task-dependent reflex responses and movement illusions evoked by galvanic vestibular stimulation in standing humans. J Physiol. , 1994; 478 (Pt 2)():363-72.

29. Day B.L., Séverac C. A., Bartolomei L., Pastor M.A.Human body-segment tilts induced by galvanic stimulation: a vestibularly driven balance protection mechanism. IN J Physiol., 1997 ; 1; 500 ( Pt 3)():661-72. 30. Eklund G. General features of vibration-induced effects on balance. J Med Sci. 1972; 77(2):112-24.

31. Roll J.P., Roll R. From eye to foot: a proprioceptive chain involved in postural control. In: Amblard B., Berthoz A., Clarac F., red. Posture and Gait: Development, Adaptation and Modulation. Amsterdam: Elsevier; 1988. s. 155-164.

32. Kavounoudias A., Gilhodes J.C., Roll R., Roll J.P. From balance regulation to body orientation: two goals for muscle proprioceptive information processing? Exp Brain Res., 1999 ; 124(1):80-8.

33. Saggini R., Speciale F., Rizzo G., Bellomo R.G., Speranza G., Di Mauro D. Flexible flatfoot treatment in children with mechanical sound vibration therapy. Italian Journal of Anatomy and Embryology, 2011 ;116(1): 158 .

34. Dichgans J., Mauritz K.H., Allum J.H., Brandt T. Postural sway in normals and atactic patients: analysis of the stabilising and destabilizing effects of vision. Agressologie, 1976; 17(C Spec No):15-24.

35. Lestienne F., Soechting J., Berthoz A. Postural re- 
adjustments induced by linear motion of visual scenes. Exp Brain Res, 1977; 27; 28(3-4):363-84.

36. Bronstein A.M., Buckwell D. Automatic control of postural sway by visual motion parallax. Exp Brain Res, 1997; 113(2):243-8.

37. Paul M., Kennedy Inglis J. T. Distribution and behaviour of glabrous cutaneous receptors in the human foot soleJ Physiol., 2002; 538(Pt 3): 995-1002.

38. Maurer C., Mergner T., Bolha B., Hlavacka F. Human balance control during cutaneous stimulation of the plantar soles. Neurosci Lett., 2001; 13; 302(1):45-8.

39. Orma E.J. The effects of cooling the feet and closing the eyes on standing equilibrium, different patterns of standing equilibrium in young adult men and women. Acta Physiol Scand, 1957; 38(3-4):288-97.

40. Asai H., Fujiwara K., Toyama H., Yamashina T., Tachino K., Nara I. The influence of foot soles cooling on standing postural control analyzed by tracking the center of foot pressure. In: Woollacoot M, Horak F, red., Posture and Gait: Control Mechanisms. II. Eugene, OR, USA: University of Oregon Books; 1992. S. 151-159.

41. Perry S.D., McIlroy W.E., Maki B.E. The role of plantar cutaneous mechanoreceptors in the control of compensatory stepping reactions evoked by unpredictable, multi-directional perturbation. Brain Res.,2000 ; 22; 877(2):401-6.

42. Do M.C., Bussel B., Breniere Y. Influence of plantar cutaneous afferents on early compensatory reactions to forward fall. Experimental Brain Research, 1990;79:319-324.

43. Knibestöl M. Stimulus-response functions of slowly adapting mechanoreceptors in the human glabrous skin area. J Physiol. , 1975;245(1):63-80.

44. Johansson R.S., Vallbo AB. Spatial properties of the population of mechanoreceptive units in the glabrous skin of the human hand. Brain Res., 1980 ; 24;184(2):353-66.

45. Johansson R.S., Vallbo A.B. Tactile sensibility in the human hand: relative and absolute densities of four types of mechanoreceptive units in glabrous skin. Journal of Physiology., 1979; 286:283-300.

46. Johansson R.S., Vallbo A.B. Tactile sensory cording in the glabrous skin of the human hand. Trends in Neurosciences., 1983;6:27-32.

47. Trulsson M. Mechanoreceptive afferents in the human sural nerve. Experimental Brain Research., 2001;137:94-102.

48. Kavounoudias A., Roll R., Roll J.P. The plantar sole is a 'dynamometric map' for human balance control. NeuroReport. ,1998; 9:3247-3252.

49. Perry S.D., Mcllroy W.E., Maki B.E. The role of plantar cutaneous mechanoreceptors in the control of compensatory stepping reactions evoked by unpredictable, multi-directional perturbation. Brain Research., 2000;877:401-406.

50. Pyykko I., Jantti P., Aalto H. Postural control in elderly subjects. Age Ageing, 1990; 19:215-221

51. Cherepakhin M.A., Purakhin Y.N., Petukhov B.N.
Human sensorimotor coordination following space flights. In: Livingston R.B. red., Life sciences and space research, vyd II, Berlin; Akademie-Verlag: 1973 s. 117-121. 52. Kavounoudias A., Roll R., Roll J.P. Foot sole and ankle muscle inputs contribute jointly to human erect posture regulation. J Physiol , 2001; 532:869-878.

\section{Correspondence address:}

Prof. Raoul Saggini

Postgraduate School in Physical and Rehabilitation Medicine, Department of Neuroscience and Imaging, G. d' Annunzio University, Chieti, Italy saggini@unich.it 